\title{
SILENT HYPOGLYCEMIA IN PATIENTS WITH DIABETES
}

\author{
Simona Clus ${ }^{1}$, Gabriela Creteanu' ${ }^{1}$, Amorin Popa ${ }^{2}$ \\ "Sf. Ioan cel Nou" County Emergency Hospital, Suceava, Romania \\ ${ }^{2}$ Faculty of Medicine and Pharmacy, University of Oradea, Romania \\ Corresponding author: \\ Clus Simona \\ Suceava, str Ion Neculce, nr 2, bl 22, sc A, ap 12 \\ Email-simonaclus@yahoo.fr
}

\begin{abstract}
Introduction. latrogenic hypoglycemia increases cardiovascular morbidity sometimes even with fatalities, and also increases cognitive disorders in most people with type 1 diabetes (T1D) and type 2 diabetes (T2D). Hypoglycemia is characterized by unawareness if the sympathoadrenal response is attenuated during the night, in autonomic neuropathy or in elderly patients. Therefore, hypoglycemia is a limiting factor in the glycemic management of diabetes.
\end{abstract}

Methods. We aimed to analyze the hypoglycemic events and the time spent with low glucose level (glucose <3.9 mmol/l) in patients with diabetes (T1D, T2D) with insulin therapy (basal or basal-bolus), in ambulatory or hospital setting. The glucose variability was assessed via the interstitial glucose concentration, measured with a Continuous Glucose Monitoring (CGM) system over 72 hours.

Results. The incidence, severity and duration of hypoglycemia are not correlated with HbAlc, disease's duration and patient's age. In patients with $T 1 D$, severe hypoglycemia is more frequent in patients with a long duration of diabetes. In this analysis, the type of basal analog insulin did not influence the presence of hypoglycemia $(p=0.7)$, but the duration of nocturnal hypoglycemia was longer with insulin glargine U100 than with insulin detemir. The basal regimen is more protective for hypoglycemia than basal-bolus insulin.

Conclusions. The study suggested that hypoglycemic events are common, silent and prolonged in 1/3 of patients with TID and T2D. The CGM system is beneficial for all patients with T1D and for patients with T2D with hypoglycemic risk and complications, to adjust medication in order to prevent cardiovascular events.

Keywords: hypoglycemia, glucose monitoring, glycemic variability, impaired awareness hypoglycemia 
INTERNAL

Original papers

\section{Introduction}

Maintaining glycemic values within the target range can prevent or reduce the severity of microvascular complications of diabetes, as many studies demonstrated (UKPDS, ADVANCE, VADT), but the benefits of glycemic control are rarely achieved for macrovascular complications (heart attack, stroke) and mortality ${ }^{(1,2,3)}$. Intensive glycemic control increases the frequency and severity of iatrogenic hypoglycemia. It is known that, for patients with T1D, the mortality due to hypoglycemia is as high as $10 \%{ }^{(4)}$. At 25 years after the publishing of the results of Diabetes Control and Complications Trial Research Group (DCCT), the high risk of hypoglycemia in the T1D group with intensive treatment represents a challenge to clarify the mechanisms of hypoglycemia in treated patients, identifying the most reliable predictors of hypoglycemia, and also the financial and human costs ${ }^{(5)}$.

Euglycemic status is maintained by the balance of insulin and glucagon; this neuroendocrine counterregulation starts when levels are lower than $70 \mathrm{mg} / \mathrm{dl}$ (3.9 $\mathrm{mmol} / \mathrm{l})$. According to $\mathrm{ADA}^{(6)}$ hypoglycemia is symptomatic (palpitations, tremor, hunger and sweating), and in moderate to severe hypoglycemia neuroglycopenic symptoms occur (behavioral changes, difficulty thinking, confusion, coma, and even death); sometimes hypoglycemia may be asymptomatic due to decreased sympathoadrenal responses. These affect $30 \%$ of adults with T1D, especially when they are associated with the presence of cardiovascular autonomic neuropathy. The absence of insulin determines a failure of glucagon release, preventing glycogenolysis from the liver and increasing the risk of severe hypoglycemia ${ }^{(7)}$. Severe hypoglycemia is more frequent in T1D, with severe consequences on heart rate variability (arrhythmias, death in bed), or on the brain. In type 2 diabetes, nephropathy and macrovascular complications, especially in older patients, with cancer or hepatic disorders, predict a moderate/severe hypoglycemia ${ }^{(8)}$.

During the night, sympatho-adrenergic symptoms are attenuated, and hypoglycemia is often prolonged for 4-8 hours ${ }^{(9)}$. The hypoglycemia has side effects on the cardiovascular system causing instability of atheromatous plaque, platelet dysfunction, hypokalemia, and catecholamine release with arrhythmias ${ }^{(10)}$. In addition, glycemic fluctuations increase the risk of endothelial dysfunction and the cardiovascular risk ${ }^{(11)}$, coronary and carotid atherosclerosis in T2D patients ${ }^{(12,13)}$. A recent study demonstrated the impact of daily glucose variability, and also in successive days, on oxidative stress ${ }^{(14)}$. The risk of progression of diabetic retinopathy and cerebral atrophy with cognitive decline 
caused by glucose fluctuations is well known ${ }^{(15)}$.

$\mathrm{HbAlc}$ is a measure for the median glycemic level, but is not adequate to identify hypoglycemia and postprandial hyperglycemia. The goal of $7 \%$ for $\mathrm{HbAlc}$ is not a good indicator of the absence of glycemic excursions ${ }^{(16)}$. Kilpatrick et al. demonstrated that in DCCT the glycemic variability measured by SD (standard deviation) and MAGE are independent predictive factors for hypoglycemia ${ }^{(17)}$.

\section{Material and methods}

This study analyzed data from 74 adults with T1D and T2D, in hospital or ambulatory care, between 2013 and 2017, in the Department of Diabetes of the "Sf. Ioan cel Nou" County Emergency Hospital, Suceava, Romania.

We analyzed the hypoglycemic events on 3-5 consecutive days ( 72 hours - 98 hours) with a Continuous Glucose Monitoring (CGM) system, with an iPro-2 professional CGM evaluation, which measures interstitial glucose every 5 minutes. For sensor calibration, the patient measured the capillary glycemia 4 times/day, preprandially and at night. Nocturnal hypoglycemia was considered between 22:00h and 07:00h.

Hypoglycemia was defined by a glycemic value $<70 \mathrm{mg} / \mathrm{dl}$. Our data includes the day with highest variability. In this study the parameters analyzed were: HbAlc, comorbidities, antihyperglycemic agents, duration of diabetes and hypoglycemic events. The statistic methods used were EXCEL and SPSS.

\section{Results}

A total of 74 subjects were included, comprising $47.3 \%$ men, $44,6 \%$ T1D, with complications - diabetic neuropathy (93.1\%), retinopathy (48.2\%), and nephropathy $(21,8 \%, 5$ patients with hemodialysis). Hypertension was the most common comorbidity, and ischemic heart disease (48.3\%) was also prevalent.

$89.5 \%$ of the patients with type 1 diabetes and $38 \%$ with type 2 diabetes had more than 1 episode of hypoglycemia in 3 days, half with moderate hypoglycemia. The proportion of patients with symptoms was only $40.9 \%$ for T2D, and $38.4 \%$ for T1D. The maximum time/day spent with hypoglycemia was on average 166.6 minutes for T1D ( $\max =531$ minutes, $\min =10$ minutes), and 72.7 minutes/day for T2D.

About $65.5 \%$ of patients with type 1 diabetes and $32.7 \%$ patients with T2D had hypoglycemia, for an average of 124 minutes and 6 minutes/night, respectively, usually asymptomatic (Table 1 ). The patients with type 1 diabetes spent more time with glucose concentrations less than $70 \mathrm{mg} / \mathrm{dl}$ (3.9 $\mathrm{mmol} / \mathrm{l}$ ) during 24 hours and at night $(p=0.00002, p=0.0007)$.

Mild hypoglycemic episodes frequently precede severe hypoglycemia, $43 \%$ of hypoglycemic events were moderate to severe, without values below $40 \mathrm{mg} / \mathrm{dl}$ measured with CGM. 32 patients had treatment with insulin detemir (11 patients with T1D), 31 patients with insulin glargine $100 \mathrm{U} / \mathrm{ml}$, and 11 patients with insulin glargine $300 \mathrm{U} / \mathrm{ml}$ (22 patients with T1D). The incidence of hypoglycemia was similar, but the prolonged hypoglycemia at night was more frequent in patients treated with Lantus in the nocturnal period ( $p=0.03$ ).

Treatment with basal-bolus insulin was associated with a high risk of hypoglycemia, especially for diurnal hypoglycemia.

The prevalence of hypoglycemia and the duration of hypoglycemia are not correlated 


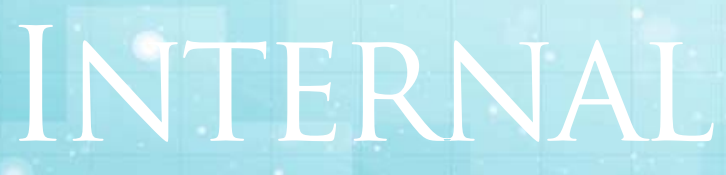

Original papers

with $\mathrm{HbAlc}$, duration of the disease and age in either type 2 diabetes or in type 1 diabetes (Table 2). In patients with type 1 diabetes, severe hypoglycemia is more frequent in patients with a long duration of diabetes.

\section{Discussion}

For cardiovascular complications in type 2 diabetes, glucose fluctuations (hypo/hyperglycemia) have a stronger impact than constant hyperglycemia ${ }^{(12)}$, and also increase inflammation with endothelial dysfunction in diabetic adolescents ${ }^{(18)}$.

Hypoglycemic events were reported by $24 \%$ to $60 \%$ patients with diabetes, three times more frequently in T1D and T2D with a long duration, on average 0.35 events/ year/ patient ${ }^{(19)}$.

In this study we recorded a higher number of hypoglycemic events than in other prospective studies because we investigated patients treated with insulin with high risk for hypoglycemia. In patients with symptoms or hypoglycemia documented by selfmonitoring, the treatment was adjusted for the next days, and that was the reason for the decrease of hypoglycemic events in the following days.

The hypoglycemia occurs at variable times/day in type 1 diabetes, frequently missed by the 3-4 glycemic monitorings/day. This is demonstrated by the monitoring of type 1 diabetes in pregnant women, who spent 10-12 hours/day with hyperglycemia (>140 mg/dl) and 2-3 hours/day with values $<70 \mathrm{mg} / \mathrm{dl}^{(20)}$. Our data demonstrated the same risk for T1D. The risk for prolonged hypoglycemia was higher among female patients with type 1 diabetes and older patients with several comorbidities, including cardiovascular disease, cerebrovascular disease, and chronic kidney disease.

Patients with chronic kidney disease or dementia who were treated with sulphonylureas and insulin have a very high risk of hypoglycemia. Four of the five patients with hemodialysis had hypoglycemia in this analysis.

Our study has some limitations due to errors of self-monitoring and device calibration. It is known that the difference between plasma glucose and interstitial glucose is $<6 \%{ }^{(21)}$. If we introduced the 4 capillary glucose measured preprandially or 2 hours postprandially, we had an optimal calibration $^{(22)}$. We will discuss the possible mechanisms which may explain the association between the type of basal insulin and the hypoglycemic events. The impact of rapid human insulin on the risk for nocturnal hypoglycemia was demonstrated ${ }^{(22)}$ and in this analysis the percentage of patients with T1D treated with insulin glargine U100 is higher than of those treated with insulin detemir. The retrospective or real-time CGM 


\begin{tabular}{|c|c|c|c|c|}
\hline & Total & T1D & T2D & \\
\hline Type of Diabetes Mellitus & 74 & 33 & 41 & \\
\hline Age (Years) & 55.6 & 40.8 & 63.13 & \\
\hline Male gender & 35 & 11 & 24 & \\
\hline Duration of DM (years) & 16.9 & 19.9 & 13.6 & \\
\hline HbAlc, mean & 9.03 & 8.93 & 9.06 & \\
\hline $\begin{array}{l}\text { Patients with nocturnal } \\
\text { hypoglycemia }\end{array}$ & $\begin{array}{c}31 \\
(41.17 \%)\end{array}$ & $14(42.5 \%)$ & $17(41.5 \%)$ & \\
\hline $\begin{array}{l}\text { Time spent with nocturnal } \\
\text { hypoglycemia (minutes) }\end{array}$ & 79.5 & $\begin{array}{c}97.5 \\
(61.5 \%>30 \mathrm{~min} \\
38.4 \%>100 \\
\mathrm{~min})\end{array}$ & $\begin{array}{c}39.4 \\
(40.9 \%>30 \mathrm{~min} \\
18.18 \%>100 \mathrm{~min})\end{array}$ & $p=0.0007$ \\
\hline $\begin{array}{l}\text { Total time spent with } \\
\text { hypoglycemia } \\
\text { (minutes/day) }\end{array}$ & 16 & $\begin{array}{c}166.65 \\
(65 \%>100 \mathrm{~min})\end{array}$ & 72.7 & $p=0.00002$ \\
\hline $\begin{array}{l}\text { Patients with diurnal } \\
\text { hypoglycemia }\end{array}$ & 32 & 21 & 11 & \\
\hline $\begin{array}{l}\text { Symptoms during } \\
\text { hypoglycemic events }\end{array}$ & 19 & 10 & 9 & \\
\hline $\begin{array}{l}\% \text { of prolonged } \\
\text { hypoglycemia (>50 } \\
\text { minutes) }\end{array}$ & $43.75 \%$ & $30.7 \%$ & $59.09 \%$ & \\
\hline Cardiovascular diseases & 42 & 6 & 36 & \\
\hline Diabetic neuropathy & 81 & 26 & 55 & \\
\hline Diabetic retinopathy & 41 & 18 & 23 & \\
\hline $\begin{array}{l}\text { Nephropathy } \\
\text { (Hemodialysis- HD) }\end{array}$ & $19(5-H D)$ & $6(3-H D)$ & $13(2-\mathrm{HD})$ & \\
\hline
\end{tabular}

Table 2. The prevalence of hypoglycemia and duration of hypoglycemia in correlation with HbAlc, duration of the disease and age in type 1 and type 2 diabetes 


\section{INTEF}

\begin{tabular}{|c|c|c|}
\hline \multirow{4}{*}{ Type 1 diabetes } & HbA1c - duration of nocturnal hypoglycemia & $p=0.27$ \\
\hline & Hb1c - duration of hypoglycemia/day & $p=0.07$ \\
\hline & $\begin{array}{c}\text { Duration of the disease - duration of total time } \\
\text { with hypoglycemia/day }\end{array}$ & $p=0.13$ \\
\hline & Duration of disease - hypoglycemic events & $p=0.58$ \\
\hline \multirow{4}{*}{ Type 2 diabetes } & HbA1c - duration of nocturnal hypoglycemia & $p=0.17$ \\
\hline & Hblc - duration of hypoglycemia/day & $p=1.25$ \\
\hline & $\begin{array}{l}\text { Duration of the disease - duration of nocturnal } \\
\text { hypoglycemia }\end{array}$ & $p=0.6$ \\
\hline & $\begin{array}{c}\text { Duration of the disease - duration of total time } \\
\text { with hypoglycemia/day }\end{array}$ & $p=0.65$ \\
\hline
\end{tabular}

Table 2. The prevalence of hypoglycemia and duration of hypoglycemia in correlation with HbAlc, duration of the disease and age in type 1 and type 2 diabetes

systems have many benefits for the assessment and the improvement of the glycemic control in type 1 and type 2 diabetes. In type 2 diabetes, CGM is indicated for patients with treatment with hypoglycemic risk, comorbidities, older and also to assess the action of new drugs ${ }^{(23,24)}$.

Silent hypoglycemia is also a manifestation of autonomic neuropathy, possibly accompanied by abnormalities in heart rate control, orthostatic hypotension, painless myocardial ischemia, or gastro-intestinal manifestations ${ }^{(25)}$. The real-time and retrospective CGM systems concomitantly used with devices for cardiovascular investigations could provide a greater insight on the mechanisms of glucose variability and the cardiovascular complications of diabetes.

\section{Conclusions}

Nocturnal and asymptomatic diurnal hypoglycemia is more frequent and severe in 
patients with T1D, independent of HbAlc value, diabetes duration and age. This complication is present in over $40 \%$ patients with T1D and T2D, without symptoms in many cases. More than $1 / 3$ of patients with T2D have minimum 1 hypoglycemic event in 3 days, often worsening cardiac and neurologic diseases and cognitive decline due to vascular damage, elevation of reactive oxygen species, hypokalemia and low-grade inflammation. The impact of severe or prolonged hypoglycemia is defining the treatment modality of older patients with T1D and T2D with comorbidities.

\section{Acknowledgement - none}

\section{Conflict of interest - no conflict of interest}

\section{References}

1. UK Prospective Diabetes Study (UKPDS) Group. Intensive blood-glucose control with sulphonylureas or insulin compared with conventional treatment and risk of complications in patients with type 2 diabetes (UKPDS 33). Lancet 1998;352:8378533

2. Busko M.-VADT at 10 years - Tight glucose control cuts cardiovascular events. Medscape, June 2015

3. Cyrus V. Desouza, Geremia B. Bolli and Vivian Fonseca - Hypoglycemia, Diabetes, and Cardiovascular Events in Diabetes Care. 2010 Jun; 33(6): 13891394.

4. Heller SR. Abnormalities of the electrocardiogram during hypoglycaemia: the cause of the dead in bed syndrome? In International Journal of Clinical Practice Suppl. 2002-Jul;(129):27-32.

5. Richard M. Plotzker - Hypoglycemia, 25 Years After DCCT-Medscape-Jun 27, 2018. p1.

6. Seaquist ER, Anderson J, Childs B, et al. Hypoglycemia and diabetes: a report of a workgroup of the American Diabetes Association and the Endocrine Society. Diabetes Care2013;36:13841395)

7. Samson WK, Stein LM, Elrick M et al. - Hypoglycemia unawareness prevention: Targeting glucagon production. PhysiolBehav. 2016 Aug 1;162:147-50. doi: 10.1016/j.physbeh.2016.04.012.

8. Silva TP, Rolim LC, SallumFilho C.et al - Association between severity of hypoglycemia and loss of heart rate variability in patients with type 1 diabetes mellitus. Diabetes Metab Res Rev. 2016 May 30. doi: 10.1002/dmrr.2830

9. Jennum $P$, Stender-Petersen $K, R a b ø l R$, Jørgensen NR, Chu PL, Madsbad S. - The Impact of Nocturnal Hypoglycemia on Sleep in Subjects With Type 2 Diabetes Diabetes Care. 2015 Nov;38(11):2151-7. doi: 10.2337/dc15-0907. Epub 2015 Sep 25

10. Frier BM, Schernthaner G, Heller S - Hypoglycemia and cardiovascular risks. Diabetes Care2011;34(Suppl. 2):S132S137pmid:21525444

11. Torimoto K, Okada Y, Mori H, Tanaka Y. Relationship between fluctuations in glucose levels measured by continuous glucose monitoring and vascular endothelial dysfunction in type 2 diabetes mellitus. Cardiovascular Diabetology. 2013;12(article 1) (PMC free article) (PubMed)

12. Gong Su, Shuhua Mi, Hong Tao, Zhao Li, Hongxia Yang, Hong Zheng, Yun Zhou, and Changsheng $M$ Association of glycemic variability and the presence and severity of coronary artery disease in patients with type 2 diabetes in Cardiovascular Diabetology 201110:19DOI: 10.1186/1475-2840-10-19

13. Xingguang Zhang, Xiuping $X u$, Xiumin Jiao, Jinxiao Wu, Shujing Zhou, and Xiaofeng Lv - The Effects of Glucose Fluctuation on the Severity of Coronary Artery Disease in Type 2 Diabetes Mellitus in J Diabetes Res. 2013; 2013: 576916., Published online Jul 7, 2013. doi: 10.1155/2013/576916 PMCID: PMC3723244).

14. Eberhard Standl, MD, Oliver Schnell, MD, and Antonio Ceriello, MD - Postprandial Hyperglycemia and Glycemic Variability - Should we care? In Diabetes Care. 2011 May; 34(Suppl 2): S120S127. Published online 2011 Apr 22. doi: 10.2337/dc11-s206PMCID: PMC3632148

15. Xingran Cui, Amir Abduljalil, Brad D. Manor, ChungKang Peng, Vera Novak - Multi-Scale Glycemic Variability: A Link to Gray Matter Atrophy and Cognitive Decline in Type 2 DiabetesPublished: January 24, 2014, http://dx.doi.org/10.1371/journal.pone.0086284

16. Engler B, Koehler C, Hoffmann C, et al. Relationship between $\mathrm{HbAlc}$ on target, risk of silent hypoglycemia and glycemic variability in patients with type 2 diabetes mellitus in Exp Clin Endocrinol Diabetes. 2011 Jan;119(1):59-61. doi: 10.1055/s-0030-1262874. Epub 2011 Jan 18

17. Kilpatrick ES, Rigby AS, Goode K, Atkin SL. - Relating mean blood glucose and glucose variability to the risk of multiple episodes of hypoglycaemia in type 1 diabetes. Diabetologia. 2007;50:255361. (PubMed)

18. Hoffman RP, Dye AS, Huang H, Bauer JA - Glycemic variability predicts inflammation in adolescents with type 1 diabetes in J Pediatr Endocrinol Metab. 2016 Oct 1;29(10):1129-1133. doi: 10.1515/jpem-2016-0139 19. Brod M, Christensen T, Thomsen TL, Bushnell DM. The impact of non-severe hypoglycemic events on work 


\section{INTERNAI}

General Reviews

productivity and diabetes management. Value Health 2011; 14: 665-71

20. Feig DS, Asztalos E Corcoy R, De Leiva $A$ et alCONCEPTT Collaborative Group. CONCEPTT: Continuous Glucose Monitoring in Women with Type 1 Diabetes in Pregnancy Trial: A multi-center, multi-national, randomized controlled trial - Study protocol. In BMC Pregnancy Childbirth. 2016 Jul 18;16(1):167. doi: 10.1186/s12884-016-0961-5.

21. Rebrin K, Steil GM.-Can interstitial glucose assessment replaces blood glucose measurement? Diabetes Technol Ther 2000;2:461-72

22. Heller $S^{1}$, Bode B, Kozlovski P, Svendsen AL- Metaanalysis of insulin aspart versus regular human insulin used in a basal-bolus regimen for the treatment of diabetes mellitus.in Journal Diabetes. 2013 Dec;5(4):482-91. doi: 10.1111/1753-0407.12060. Epub 2013 May 7.

23. Toschi E, Wolpert H. - Utility of Continuous Glucose Monitoring in Type 1 and Type 2 Diabetes in Endocrinol Metab Clin North Am. 2016 Dec;45(4):895-904. doi: 10.1016/j.ecl.2016.06.003. Epub 2016 Sep 28.

24. Alfadhli E, Osman E, Basri T - Use of a real time continuous glucose monitoring system as an educational tool for patients with gestational diabetes. In Diabetol Metab Syndr. 2016 Jul 26;8:48. doi: 10.1186/s13098-016-0161-5. eCollection 2016

25. Poantă L, Porojan M, Clus S, Dumitraşcu DL Cardiovascular autonomic neuropathy in diabetes mellitus.. Rom J Intern Med. 2009;47(4):403-7. 